\title{
REVISITANDO INTERPRETAÇÕES SOBRE O CAMPESINATO: CONSTRANGIMENTOS E PERSPECTIVAS DE AUTONOMIA
}

\author{
Henrique Carmona Duval \\ Vera Lúcia Silveira Botta Ferrante* \\ Sonia Maria Pessoa Pereira Bergamasco ${ }^{* * *}$
}

Resumo: O artigo é fruto de uma discussão sobre a condição camponesa no Brasil. São resgatados alguns elementos da teoria do campesinato, desde as correntes de pensamento que apontavam para o fim dessa categoria social e, contrariamente, os que apostaram na reconstrução e adaptação dos camponeses brasileiros na contemporaneidade. Nesse balanço, discutem-se as teses do isolamento e da incapacidade racial, do campesinato enquanto classe social, a dependência dos camponeses em relação ao mercado e ao Estado, o campesinato enquanto parte do setor de subsistência da economia brasileira. Tudo isso para afirmar sua posição historicamente secundária e subordinada nos planos de desenvolvimento econômico, mas que cada vez mais merece reconhecimento social.

Palavras-Chave: Teoria do campesinato. Recampenização. Subordinação social.

Abstract: This article discusses elements of the peasant condition in Brazil. There have been rescued some elements of the peasantry theory, since the currents that pointed to the end of this social category and, conversely, those who bet on the reconstruction and adaptation of Brazilian peasants nowadays. In this balance, we discuss the thesis of isolation and racial disability, the peasantry as a social class, the dependence of farmers on the relationships with the market and the state, and the peasantry as a part of the subsistence economy sector in Brazil. All this to state its position historically secondary and subordinated on the plans of economical development, but which increasingly deserves social recognition.

Keywords: Peasantry theory. New peasants. Social subordination.

\footnotetext{
${ }^{*}$ Doutor em Ciências Sociais no IFCH/Unicamp, pesquisador do Programa de Pós-Graduação em Desenvolvimento Territorial e Meio Ambiente do Centro Universitário de Araraquara (Uniara). E-mail: henriquecarmona@hotmail. $\underline{\text { com. }}$

** Pesquisadora 1A do CNPq, coordenadora do Programa de Pós-Graduação em Desenvolvimento Territorial e Meio Ambiente do Centro Universitário de Araraquara (Uniara). E-mail: dtmeioambiente@uniara.com.br.

${ }^{* * *}$ Professora Titular - Faculdade de Engenharia Agrícola/Unicamp - Bolsista CNPq de Produtividade em Pesquisa e Bolsista CAPES/Programa Nacional Professor Visitante Sênior PNPVS/UFSCar - Araras. E-mail: sonia@,feagri. unicamp.br.
} 
ve a pequena agricultura existente já no interior das plantations escravistas e voltadas ao abastecimento

O presente artigo faz parte de uma revisão bibliográfica acerca da teoria do campesinato no Brasil empreendida por Duval (2015), com o intuito de resgatar elementos fundamentais de análise dessa categoria e também de reconhecer a existência de grupos camponeses na contemporaneidade. Certamente, não temos a pretensão de abarcar todos os aspectos dessa complexa construção, muito menos realizar uma abordagem calcada em uma tipologia sobre os camponeses. Propomos, primeiramente, discutir questões polêmicas e controvérsias que remetem ao preconceito contra a população rural. Posteriormente, abordamos como pessoas com diferentes perspectivas de vida podem ser enquadradas enquanto classe social, porém muito mais identificadas com a vivência de uma condição camponesa.

Antes de tornar uma definição conceitual demasiadamente rígida sobre o campesinato, optamos pela condição camponesa, que é a posição social definida pelo capital na qual os camponeses se encontram. Nessa condição, os camponeses estão subordinados pelas relações de propriedade e de produção agropecuária e seu trabalho e lucro são apropriados por fazendeiros, latifundiários e pelo capital agroindustrial. Com a modernização conservadora da agricultura, a tendência dos grupos de camponeses passou a ser a saída do campo ou sua integração aos complexos agroindustriais. No entanto, ao mesmo tempo, existem nessa condição grupos que resistem no campo e que lutam para ter uma margem para a livre deliberação em suas práticas cotidianas - embora esta também possa ser uma liberdade subordinada pelo capital.

Ao final, são feitos apontamentos entre aquilo que se entende por setor de subsistência da economia brasileira e sua relação com os camponeses. Trata-se da permanente existência de pessoas em um setor secundário na economia brasileira, aquele que envolinterno da colônia. Muitas vezes não reconhecido ou esquecido na informalidade, este setor é um elemento fundamental para a compreensão de dinâmicas rurais e urbanas no Brasil.

\section{OS ENFRENTAMENTOS INICIAIS PARA OS ESTUDOS DO CAMPESINATO BRASILEIRO}

Segundo Queiroz (1976), o meio rural brasileiro começou a ser estudado pela teoria social em fins do século XIX, desde quando se destacaram duas correntes explicativas. Uma, cuja hipótese central, sinteticamente, considerava que o rural era povoado por uma mestiçagem que atrapalhava o desenvolvimento do país, no sentido do progresso. Muita coisa se explicava, nessa corrente, a partir da ideia de que "(...) o mestiço era tido como racial e fisicamente desequilibrado" (1976, p.7). Claramente, os aspectos da biologia do mestiço eram associados à preguiça, à vadiagem e à inaptidão ao trabalho.

Crítica a esses estudos, a autora afirmou que, primeiro, a questão racial é relegada àquela dimensão preconceituosa, a de que os negros são inferiores e não aptos a um trabalho regular. Tal argumento não fazia senão justificar a subjugação dos mestiços a um fazendeiro, a fim de que tivessem disciplina para o trabalho e o país pudesse "progredir", sem se discutir a perspectiva dos trabalhadores em relação à questão fundiária e a seus direitos, bem como sua capacidade de trabalho e de organização.

A segunda corrente apoiava-se no isolamento das populações rurais para explicitar suas parcas contribuições à integração e ao desenvolvimento brasileiro. Essa constatação encontrava razão na falta de infraestrutura no meio rural, como estradas, comunicações e instituições, como escolas e hospitais, bem 
como na própria falta de registro e mapeamento dos povoamentos existentes. Ou seja, o efeito da teoria não avançava no reconhecimento das populações rurais em si, mas as colocava em relação ao desenvolvimento econômico brasileiro: o modelo de desenvolvimento fundamentado nos grandes latifúndios e na produção agrícola para exportação. A racionalidade econômica na qual os povos e comunidades rurais se inseriam e eram inseridos era o principal critério para definir o isolamento. Porém, à época, "ninguém procurou definir o que significa 'distância' ou 'isolamento' em termos de vida cabocla real ou da maneira de pensar dos indivíduos que a essa vida estão ligados." (QUEIROZ, 1976, p.9).

Queiroz afirma que a maioria dos estudiosos mal saía a campo para vivenciar a realidade e parecia ignorar registros de viajantes, memorialistas, romancistas e folcloristas, que apontavam a rica produção de alimentos e a medicina tradicional, bem como a integração de comunidades locais em um âmbito regional. Portanto, a compreensão do meio rural foi estabelecida, majoritariamente, a partir de uma visão externa, afastada e, no mínimo, desinteressada politicamente. Na perspectiva de que os povoados e grupos rurais estavam fadados a ficarem fechados em si mesmos, até seu sacrifício "nos altares do capitalismo", produziu-se uma das principais armadilhas interpretativas na época, segundo a qual o campesinato iria simplesmente desaparecer.

Supostamente, não havia expectativas nem de se crescer demograficamente nem de os camponeses se tornarem agentes econômicos expressivos, devendo suas terras servir à produção em escala. Ou seja, eles perderiam definitivamente o meio rural como local de moradia, de trabalho e para a produção agropecuária. Os fluxos migratórios ligados à exploração econômica e aos ciclos de desenvolvimento no Brasil - por exemplo, da cana, do ouro, do café e da borracha - expuseram as relações de subordinação econômica dos povoados locais em relação ao território mais amplo, controlado e explorado pelas elites agrá- rias burguesas. Para Wanderley (2003), o campesinato não é isolado "por natureza". Essa é uma ideia com base nas primeiras sociedades camponesas, as civilizações e culturas camponesas. Porém, os camponeses empreenderam mudanças e articulações no processo de modernização. Eles mantêm laços com as sociedades modernas, envolvimentos, sobretudo culturais, políticos e mercantis, ainda mais recentemente com as novas tecnologias da informação.

Um estudo fundamental contra a tese do isolamento é o de Antônio Cândido (1979), que mostra como os caipiras se organizavam em vizinhança, como os bairros rurais, nos quais existia uma noção de pertencimento e distinção em relação a outras pessoas e outros bairros, no interior da mesma região em que viviam. Tal sentimento era primordial para a configuração de um grupo social numa localidade que não estava isolada. Cândido mostra que nesses lugares se desenvolveu uma forte sociabilidade nas relações entre as pessoas, no interior da região e para fora dela. A vida dos moradores extrapolava a dualidade fazendeiro e trabalhador sem terra, bem como suas relações ultrapassavam a localidade, pois conheciam e circulavam por várias regiões e realidades socioeconômicas.

Para Cândido (1979), as atividades econômicas e religiosas eram as duas principais formas de integração dos camponeses, que expressavam suas lutas por melhores condições de vida. As mais frequentes contra os interesses dos senhores de terras foram as econômicas, enquanto as religiosas tinham maior alcance para além da sociabilidade local. Queiroz (1976), no entanto, alerta que essas manifestações nunca tiveram o propósito de mudar a estrutura das hierarquias ou visaram ao crescimento de um grupo político que disputaria o poder ou, pelo menos, nunca chegaram perto disso. Mas, sim, mudavam, ainda que provisoriamente, certos espaços locais de decisão política e de reivindicações. Discussão que, de certa maneira, volta-se ao argumento sobre a ausência de consciência de classe do campesinato, uma vez que as repercussões de suas manifestações se atinham ao 
âmbito das próprias comunidades e sem com isso lograr melhores posições nas relações sociais mais amplas.

Outra ideia bastante recorrente nos estudos sobre o meio rural brasileiro era a de que o Brasil apresentava uma estrutura social dual, ou seja, na qual parecia haver apenas duas camadas sociais. $\mathrm{Na}$ verdade, o recorte entre classes proprietárias e expropriadas dos meios de produção tende a retirar as camadas intermediárias, sobretudo as diferentes camadas de camponeses. As camadas intermediárias eram reconhecidas do ponto de vista étnico, não do socioeconômico, muito embora se reconheça uma camada intermediária, por exemplo, de mulatos e mestiços que se incorporam ora às camadas superiores, ora às camadas inferiores da sociedade, a depender de situações e interesses específicos e, sobretudo, do nível de formação que possuíam.

Para Martins (2002, p.54): “Quem não pensava através da categoria 'classe operária', pensava através da categoria 'pobre'". No caso, o pobre rural fadado ao desaparecimento e à proletarização. Para esse autor, a continuidade do camponês tratava-se mais de conjunturas particulares de indivíduos e grupos de camponeses do que a permanência estrutural de toda a categoria.

Por isso, a consciência camponesa tende a ser uma consciência dessa expulsão, uma consciência de fim de era, de fim dos tempos, porque de fato expressa episódios de supressão da condição camponesa. Não é incomum que a consciência dessa finitude assuma a dimensão de uma consciência de catástrofe, de um "fim final", de apocalipse dos trabalhadores da terra. De fato é isso que, individualmente, tende a acontecer (MARTINS, 2002, p.98).

Porém, é justamente essa consciência do "final" absoluto a grande armadilha conceitual. É claro que o campesinato passou (e passa) por violentas cri- ses de sobrevivência e isso ocorre tanto em termos estruturais, que orientam ou tendem a uma expropriação definitiva da terra, como sua possível adaptação no mundo contemporâneo se dá por meio de uma tensa relação de exploração capitalista que aos poucos the enfraquece. No entanto, seria muito mais sensato falar em recriação e mesmo diferenciação da categoria do que aquela concepção fatalista, porque suas formas de produção foram redefinidas em função de uma estrutura social comandada pela reprodução do capital (MOURA, 1986, p.19). Contra essa armadilha, atualmente, autores como Van der Ploeg (2008) usam a noção de "recampenização" para expressar a reconstrução da categoria na contemporaneidade.

Questões de Classe nA TEORIA DO CAMPESINATO E A DIVERSIDADE NO PENSAMENTO BRASILEIRO

Para adentrar nessa problemática, faz-se uma breve discussão sobre as diferenças entre classes operárias e camponesas no Brasil, dentre as relevantes contribuições de José de Souza Martins para o estudo do campesinato. $\mathrm{O}$ autor justifica sua escolha pelo fato de que:

Na diversidade de situações sociais presentes nas inquietações dos que compareciam a esses encontros ${ }^{1}$, escolhi a categoria de "classe social" para desenvolver uma reflexão comparativa entre "operários" (em relação aos quais havia "teorias" conhecidas) e "camponeses" (os desconhecidos e portadores do desafio ao entendimento). Era um modo de tratar de uma característica fundamental da sociedade contemporânea, que é a da diversificação social, não só a das gradações de riqueza e pobreza, mas também diversificação das inserções sociais, das

${ }^{1}$ Os encontros a que o autor se refere nessa passagem eram atividades de formação e diálogo com trabalhadores rurais das pastorais e sindicatos, durante a década de 1970, nas quais ele e outros intelectuais, como Carlos Rodrigues Brandão, contribuíram para a conscientização política de suas condições sociais (MARTINS, 2002). 
situações sociais, das mentalidades, das possibilidades e limites de atuação social e histórica das diferentes classes e categorias (MARTINS, 2002, p.54)2.

\section{(...)}

No geral, havia nos agentes de pastoral e nos militantes políticos a propensão de estender aos camponeses o conhecimento que se tinha sobre os operários, especialmente no que se refere ao entendimento doutrinário e ideológico. $\mathrm{Ou}$ de cobrar dos trabalhadores rurais comportamentos operários e consciência operária. Em outras palavras, os agentes tinham expectativas de que os trabalhadores rurais "existissem" e se comportassem como classe social, no padrão próprio de conduta da classe trabalhadora gestada na fábrica, na empresa capitalista (MARTINS, 2002, p.54-55).

Apesar dessa orientação por parte dos agentes sociais, o autor reconheceu que por toda a parte se recolhiam evidências empíricas, sobretudo dos agentes da Igreja e da Pastoral da Terra, mas também dos sindicatos e universidades, sobre a permanência da condição camponesa e das diferenças em seu interior. A própria organização da luta dos trabalhadores rurais estava polarizada entre o assalariamento/proletário e a recampenização, o que contribuía para o uso genérico de uma classe social envolvendo tanto aqueles que queriam direitos trabalhistas para o assalariamento quanto os que queriam a terra, os que queriam poder "botar" roçado. Martins (2002) destacou a necessidade de enxergar as diferenças entre grupos sociais camponeses e operários.

A primeira distinção é quanto ao próprio vínculo com o capital. Para o operário, é um vínculo direto de assalariamento, por meio daquilo que ele recebe em pagamento em dinheiro. O operário dispõe apenas de sua força de trabalho e o produto de seu ${ }^{2}$ Essa citação foi inserida também para justificar o uso da categoria classe social, que era a categoria pela qual se debatia o campesinato no Brasil. Porém, havia uma necessidade de expor suas diferenciações, contra a tendência de sua homogeneização, como fez Martins. trabalho surge como propriedade do capitalista. Se ele pode ser considerado juridicamente livre para vender sua força de trabalho a quem quer, tem-se em vista que seu trabalho é dependente e subordinado. Portanto, ele é "livre" juridicamente apenas para vender sua força de trabalho. Mas suas relações de trabalho são regidas contratualmente, ou seja, por instrumento legal que arbitra os (des)acordos entre o indivíduo operário e o capitalista e que, supostamente, deveria prever igualdade de condições jurídicas, embora materialmente diferentes. Daí surgem relações assimétricas, apesar de o operário deter esse status de trabalhador livre. No caso do trabalhador rural assalariado, tratava-se de uma liberdade subjugada ao sistema de poderes e controles das agroindústrias que, além de se submeter por longo período a um pagamento por tonelada - situação que se presta a roubos e fraudes - o assalariamento tem que se subordinar à dureza e crueldade das regras que regem a produtividade sob o jugo da exploração capitalista.

Já o vínculo do camponês com o capital, para Martins, dá-se por diferentes razões, mas não tem como princípio básico a venda da força de trabalho como o operário. O trabalho do camponês, pelo menos aquela parte dedicada ao seu roçado, tem um caráter independente, pois o que ele vende é o fruto do trabalho, não o trabalho em si. Mesmo que a terra seja alugada, ele poderá usá-la como sua por determinado período, valendo-se de seus conhecimentos e decidindo o que e como fazer. É um tipo de subordinação formal ao capital, quando o capital não domina o trabalho completamente e coexistem formas não especificamente capitalistas, ou seja, quando o camponês detém parcela de autonomia sobre o processo de trabalho em sua terra ou em terra que usa. Para Martins (2002), existe uma "conflitividade" um pouco diferente das relações entre o capital e o trabalho no caso do campesinato, que é permanente e que se dá justamente nas relações de propriedade de terras.

Martins explica que o tipo ideal do camponês é aquele proprietário de terra e dos meios de produ- 
ção, mas que existem distintas maneiras de usufruto de uma terra, sobretudo aquela caracterizada como arrendamento e o aluguel da terra. $\mathrm{O}$ camponês paga ao proprietário por dias de trabalho ou em produção (este mais conhecido como parceiro ou meeiro), ou mesmo em dinheiro. Em todos os casos, há dependência das relações com grandes proprietários e exploração do trabalho camponês, mas há também uma parte de tempo para exercer um trabalho mais livre. Para Martins (2002, p.61), trata-se de forma de trabalho semelhante às sociedades feudais, no entanto, com novas diferenças. Por exemplo, na sociedade capitalista essa forma exclui os direitos de copropriedade que havia para membros da comunidade camponesa na relação com o senhor feudal. O que vale destacar é que o camponês tem ainda uma forma de trabalho familiar. Geralmente outros membros da família estão envolvidos no trabalho na terra, ou mesmo de outros membros externos à família que cumprem essa função, renumerados monetariamente ou não. Há momentos em que o trabalho coletivo é de fundamental importância para não se perder uma colheita ou deixá-la estragar, situação que tradicionalmente envolvia um tipo de trabalho solidário de ajuda mútua entre membros familiares, da vizinhança e da comunidade do entorno em mutirões de trabalho (CÂNDIDO, 1979).

Para os camponeses, é muito mais fácil perceber que eles se constituem enquanto grupos sociais através de séculos e de geração em geração, ao haver maior coesão entre as famílias em suas práticas e sociabilidades, enquanto nos lugares mais urbanizados e industrializados, a tendência é haver famílias cada vez menores e nucleares. Martins afirma que os filhos de operários são igualmente mais susceptíveis ao deslocamento em função do mercado de trabalho do que os filhos de camponeses. Isso porque a vida do operário está mais condicionada às variações desse mercado, enquanto a vida do camponês está mais voltada à sua família e à comunidade, independentemente de sua inserção no mercado:
Mesmo que cada vez mais alcançado pela dispersão e pelas migrações que a pobreza e o caráter cíclico da produção combinados viabilizam e induzem, a família e a comunidade continuam sendo grupos sociais de referência do trabalhador rural. Mesmo definitivamente na cidade e fora da agricultura, quem saiu do mundo rural continua por longo período ainda mantendo essas referências sociais (MARTINS, 2002, p.79-80).

Outro ponto de diferenciações é a suposta igualdade jurídica das relações de trabalho dos operários que mascara as desigualdades em que elas se encerram. Primeiro pelo fato de que já está totalmente afastado dos meios de produção, portanto só lhe resta vender a força de trabalho. "No mundo do operário, $o$ trabalho se toma separado do produto do trabalho. É como se ele tivesse uma existência própria, como se ele fosse a própria coisa, não sendo, ao mesmo tempo, coisa própria de quem a tem" (MARTINS, 2002, p.68, grifos no original). Para o capitalista, o trabalho operário é uma mercadoria que se compra. $\mathrm{O}$ capitalista sobrevive do trabalho excedente do operário e este, por sua vez, depende do salário para sobreviver. Se esta é uma relação de dependência mútua, é significativamente desfavorável ao operário por existir um exército reserva de mão-de-obra, enquanto as possibilidades de trabalho em diferentes lugares não são tão grandes, sobretudo àqueles que se especializam em determinados ofícios ou àqueles que assumem postura crítica às condições de trabalho, se envolvem em greves e acabam entrando em "listas negras" dos proprietários dos meios de produção (SIGAUD, 1979; FERRANTE, 1992).

Para o camponês, a força de trabalho não é separada de seu produto, pois, ao final de uma colheita, esta é percebida ao mesmo tempo como sua e fruto de seu trabalho, cuja venda ele mesmo vai negociar ou consumi-la. Assim, o trabalho, de caráter familiar e para a reprodução familiar, é para ela mesma, embora isso não signifique que esteja apartado das relações 
com o mercado e com o Estado. Para Martins, de várias maneiras o camponês e seu trabalho estão articulados ao mercado e à lógica monetária, na venda e na compra de mercadorias, embora ele seja produtor direto de muitos ou poucos itens necessários à vida. Outras vezes, o dinheiro não surge de outra forma além de nominal, ou seja, o camponês estabelece relações de troca de produtos com valores monetários determinados, nas quais não necessariamente há dinheiro diretamente envolvido, como a troca e a doação de alimentos e de trabalho.

Ao invés de vender a força de trabalho, o camponês vende "aquilo que excede suas próprias necessidades de consumo" (MARTINS, 2002, p.66), tendo por base o cálculo das necessidades básicas de sua família. Por exemplo, ele retém uma parcela dos produtos necessários para consumo direto e outra para venda. Esse cálculo é feito com base nos próprios padrões de vida esperados e por meio de regras próprias, com elementos livres da mediação do mercado, embora na prática o cálculo acabe sendo mediado pelo mercado. Para Wanderley (2009), não se escolhe entre venda e consumo individualmente, mas, sobretudo, como resultado da necessidade em adquirir os demais itens, aqueles que não se produz diretamente, necessários à sobrevivência. Essa dependência do camponês em relação ao mercado será retomada à frente. $\mathrm{O}$ importante a reter agora, com base em Martins, é que para os camponeses existe uma infinidade de situações na mediação com o mercado no tempo e no espaço - ou seja, em diferentes tempos sociais e dentre os mesmos grupos sociais. Nessa infinidade de situações, há em comum as mudanças entre o que é destinado ao consumo e à venda, a alternatividade a que se refere Garcia Jr. (1983), e o grau de especialização dos membros familiares, ou seja, a incorporação da divisão social do trabalho na família, em razão de dinâmicas demográficas (saída dos filhos), geracionais (envelhecimento) e de relações de gênero em seu interior.

O operário coloca-se na sociedade mais expli- citamente porque seu trabalho é social, é uma parcela de um trabalho que resulta num todo social e que lhe restitui uma parte em salário, daquela riqueza que todo o trabalho social resulta. Para o camponês, nem todo trabalho ou tempo de trabalho é dedicado à produção de mercadorias; por isso, em momentos de crise econômica e de desemprego, ele tem como recorrer às relações familiares para produção de itens necessários à sobrevivência, diferentemente do operário. Para o camponês: "não é o vínculo de alguém mergulhado diretamente no mundo que o capital criou." (MARTINS, 2002, p.79). Quanto mais o camponês está imerso na produção de mercadorias, no entanto, tanto mais ele é susceptível às incertezas do mercado. Em ambos os casos: "A lógica de uma modalidade de relação social tende a submergir na lógica daquela que domina, no caso a relação capitalista de produção.” (MARTINS, 2002, p.75).

Portanto, o operário está em uma condição objetiva muito mais individualizante em relação ao camponês que tem sentimento e pertencimento comunitário. Ainda que o campesinato não tenha, individualmente, como o operariado, uma relação direta de antagonismo de classe, pelo menos não em suas percepções imediatas e, sobretudo, quanto a seu trabalho e sim pelas relações de propriedade: "Isto é, sua reprodução social não é significativamente atravessada e ameaçada pela presença imediata da outra classe social, a classe que o explora" (MARTINS, 2002, p.82). Pois o campesinato é, no limite, produtor de seus meios de vida e não depende exclusivamente da mediação direta com o mercado para sua reprodução social.

Isso faz que as lutas camponesas contra sua exploração adquiram feições pré-políticas, no intuito de negar o capitalismo ao invés de superar ou transformar as condições objetivas, diferentemente do proletariado que, por sua existência estar basicamente condicionada à exploração capitalista, é a classe que melhor percebe e realiza as lutas sociais contra as condições de existência dos trabalhadores no capitalismo 
(IANNI, apud MARTINS, p.83). Portanto, as lutas dos camponeses são mais para a manutenção da condição camponesa e pela terra. Mas o capital precisa se apropriar também do trabalho do camponês, além de seus produtos. Isso ocorre progressivamente, no processo de amadurecimento das forças produtivas capitalistas e depende do estágio de desenvolvimento dessas forças em um contexto específico. Ocorre quando os processos produtivos em uma pequena propriedade são completamente dependentes da orientação do mercado, como é o caso de famílias dependentes da integração agroindustrial para sua reprodução. Trata-se, obviamente, de conjunturas políticas e econômicas, em um país ou região, que ocasionam esse tipo de situação e influenciam as perspectivas de futuro das famílias rurais.

Outra diferenciação importante é em relação à classe em si e para si. Ao que tudo indica, o campesinato é classe em si, mas não para si. Trata-se de uma consciência de classe cujo conflito nem sempre é presente nas relações de trabalho cotidianas, mas nas relações de expropriação da terra e de propriedade. A exploração de seu trabalho se dá pela renda da terra, mas também não implica que o camponês não seja explorado como o operário quando é assalariado rural ou mesmo urbano. Pois, na realidade, os agentes sociais do campesinato transitam entre uma e outra situação ${ }^{3}$, sua proletarização não é definitiva e o retorno à terra continua em seu horizonte (FERRANTE, 1992). No entanto, o conflito de classe para essa categoria se expressa mais na posse da terra e na exploração da renda da terra.

Para Martins, o campesinato é classe em si pela maneira como se insere no processo histórico, pelas próprias representações que faz de si mesmo, ou seja, o reconhecimento de uma identidade cam-

\footnotetext{
${ }^{3}$ Uma categoria que expressa bem essa ideia é a de camponeses migrantes, conforme Meneses (2002). Segundo a autora, os homens saem de sua casa nas comunidades rurais rumo ao corte de cana em regiões de plantations e, nas entressafras, retornam com algum capital para reproduzir o modo de vida camponês em seus locais de origem.
}

ponesa. Mas não é classe para si, pois supostamente não tem consciência de classe. Esta só poderia existir quando a força de trabalho fosse convertida em mercadoria, situação na qual se sabe como é retirada a exploração capitalista de seu trabalho. Além disso, não é classe para si por não frequentar os espaços em que as contestações são feitas, as praças, as ruas etc. O camponês vive e trabalha no mesmo lugar, um lugar afastado dos grandes centros, no qual poucos, sobretudo agentes do Estado, adentram as porteiras e a intimidade.

No entanto, Moura (1986, p.52-53) afirma que é marcante a consciência do camponês brasileiro sobre a exploração a que está submetido e que: "A falta de uma visão global da sua condição subalterna está também presente nas representações de outras classes sociais e não deve ser tomada como uma espécie de traço natural da consciência conservadora camponesa". Mais à frente, essa autora resume que: "a ampliação do capitalismo enquanto sistema de produção pressupõe não só a extração do sobre trabalho operário, mas a captação do sobre trabalho camponês, processo que sempre se baseia na violência política e militar" (MOURA, 1986, p.63). Fato que certamente trouxe inúmeros constrangimentos para a organização por parte daqueles grupos camponeses que procuravam fugir à lógica coisificante da integração agroindustrial ou que lutavam para o reconhecimento de suas terras e direitos.

CAMPOneses E OPERÁRIOS: DIFERENÇAS E CONTINUIDADES

Como bem lembrou Thompson (1987), há várias formas de expressar as diferenças e as continuidades entre camponeses e operários. A máquina a vapor não é somente genitora da sociedade capitalista industrial, mas também responsável por novas relações sociais, instituições e hábitos culturais. "Mas 
isso pode levar ao menosprezo da continuidade das tradições políticas e culturais na formação das comunidades de classe operária" (p.16). A relação de exploração muda na fábrica, não há mais como manter os mesmos padrões de paternalismo e deferência como antes, então se torna mais do que a soma de injustiças e antagonismos para com as classes trabalhadoras, pois está relacionada à propriedade e ao poder numa esfera estatal. Nesse sentido, não existe salário justo ou normas e costumes morais, apenas imposição. "O processo de industrialização precisa impor o sofrimento e a destruição de modos de vida estimados e mais antigos" (THOMPSON, 1987, p.29).

O autor exemplifica que os cercamentos - a tomada de posse de terras, verdadeiras guerras contra os camponeses - eram vistos na Inglaterra menos pela dureza sofrida pelos pobres das aldeias do que pelo sucesso em alimentar a população crescente dos distritos industriais. Então, o período de intensa industrialização que vai de 1790 a 1840 pode ser visto como um tipo de desenvolvimento econômico sem precedentes naquele país, e não como gerador de catástrofe e de miséria para os trabalhadores urbanos e rurais. Existiam indicadores importantes, como o preço do trigo e o crescimento econômico, pelos quais afirmavam-se que a situação de trabalho na indústria era melhor do que a anterior, no campo. Então, é de se questionar: "Qual a alquimia social por trás da transformação dessas invenções destinadas a poupar o trabalho humano em máquinas de empobrecimento?" (THOMPSON, 1987, p.30).

$\mathrm{Na}$ condição de camponeses, poderia se justificar a miséria com fatos como uma colheita ruim, mas na condição seguinte o que realmente está em jogo é uma complexa relação humana que envolve direito, propriedade e poder. Igualmente, os argumentos sustentados nos fluxos econômicos fomentavam a expropriação de direitos de camadas menos favorecidas e escamoteavam os movimentos sociais em benefício do lucro de poucos que exerciam os cercamentos. Na nova lógica, "Se os alimentos fossem abundantes, 'eles' lucravam. Se fossem escassos, alguns 'deles' lucravam ainda mais" (HAMMOND apud THOMPSON, 1987, p.32). Então, o autor se volta às condições camponesas para falar da menor miséria sofrida por essas categorias menos favorecidas e subalternas: "A terra é sempre capaz de tirar o homem do sofrimento, caso ele tenha uma pá e uma enxada". "Quando a lei (restauração dos velhos tempos) dos antigos dias santos, antiga justiça, quando cada um sobrevivia do próprio suor, quando tecelão podia se espreguiçar em seu campo e a lei reconhecia o direito à abundância”. Não é a toa que Thompson identificou que a luta pela terra exercida nas cidades se dava pelos filhos e netos de camponeses de outrora, agora urbanizados e conscientes dos efeitos do desenvolvimento econômico com os cercamentos e a industrialização agrícola, depois que estavam livres da sombra dos proprietários rurais. E suas lutas eram diretamente relacionadas aos direitos consuetudinários camponeses (MOURA, 1986, p.34-35).

Retomando as relações do camponês com o capital no Brasil, pode-se afirmar que não houve uma economia camponesa como base das relações sociais. Como afirmou Caio Prado Jr. (1966), a população rural no Brasil não teve a mesma formação histórica que o campesinato europeu, por estar desde sempre submetido - política, social e economicamente - aos governos e às classes dominantes das potências europeias, bem como aos proprietários de terras que promoveram uma expansão capitalista nas Américas. Para esse autor, não estariam os camponeses brasileiros aptos a se tornarem produtores livres, por falta de condições materiais e simbólicas. Nesse sentido, a luta pela terra poderia representar um retrocesso quanto aos níveis de produtividade que a agricultura brasileira já havia conquistado. Posição controversa que entra e sai de cena na análise da questão agrária. Porém, outros estudiosos enriqueceram o debate acerca do acesso à terra e sobre o trabalho rural familiar no Brasil, bem como a existência “(...) do que havia sido admitido como expressão de uma economia 
camponesa, existente fora da grande propriedade." (WANDERLEY, 2009, p.76).

Os autores que continuaram a estudar os grupos rurais pela recriação do campesinato tinham como perspectiva a combinação de modos de produção. Ou seja, apesar das plantations, existia uma estrutura de produção baseada no trabalho familiar que justificava afirmar o campesinato como modo de produção subordinado. Essa estrutura tinha seu lugar nas relações de produção ampliadas, mas um lugar delimitado e secundário em relação às grandes propriedades e às prioridades da produção das principais lavouras para exportação. Por isso, as especificidades do campesinato enquanto classe, se olhadas mais de perto, poderiam expor as várias divisões possíveis e as contradições no interior da classe, mas permaneceriam homogêneas diante do modo de produção dominante (VELHO, 2009). Sua posição e oposição social, enquanto classe subordinada, seriam suficientes para considerá-la uma classe política, por vezes denominada pré-política, pois lhe faltaria organização.

Se os trabalhadores das plantations não podiam ser considerados camponeses, a própria evolução capitalista nas plantations transformaria parte deles em proletários e outra parte em camponeses. Conforme Sigaud (1979, p.44): “(...) se uma das vertentes do processo de mudança foi a transformação do morador em mero vendedor de força de trabalho, a outra vertente teria sido a constituição de um campesinato marginal à plantation, a partir da fragmentação de antigos engenhos que foram então vendidos em pequenos lotes por ser esta a modalidade mais rentável".

Nesse sentido, Otávio Velho distinguiu também o campesinato marginal e o de fronteira. Quanto ao primeiro, ficava literalmente às margens das plantations e funcionava como mão-de-obra reserva a elas, produzindo sua subsistência, comercializando seu excedente nas intermediações ou, aos poucos, abandonando essa prática. $\mathrm{O}$ de fronteira vivia em regiões distantes dos domínios dos latifundiários, pelo menos até que a expansão das plantations lhe alcançasse e causasse novos ciclos migratórios para mais distante ou a subordinação. A produção de subsistência, nos casos de campesinato que persistia ou se recriava, viria a ser uma necessidade do mercado interno, em substituição à produção que antes ocorria no interior das plantations, antes do processo de expulsão de seus moradores. Moacir Palmeira (2009) identificou que a produção de alimentos do campesinato marginal, comercializada nas feiras da Zona da Mata pernambucana atendia, sobretudo, ao mercado de ex-moradores dos engenhos e, além disso, esse tipo de produção passou a ser mais relevante para o mercado interno dos centros urbanos a partir de 1930, segundo Wanderley (2009), pois passou a haver mais programas de urbanização e industrialização, assim como a abertura de estradas pelo país.

Os estudos apontavam dois pontos em comum: um deles era o reconhecimento do avanço da expropriação dos meios de produção de grande parte dos produtores familiares, o que incluía a expulsão dos moradores das colônias nas fazendas. Outro, a permanência da condição camponesa em diferentes graus nos grupos rurais, mesmo com as mudanças sociais. Em todo o caso, havia uma posição subordinada dos camponeses ao capitalismo, seja nas representações acerca do modo de vida urbano/industrial, seja nas relações de trabalho com a necessidade cada vez maior de sua vida estar submetida à lógica monetária. Mas também eram mantidas as características da produção e da reprodução social camponesa, o sítio camponês como local de trabalho e/ou moradia, a utilização de mão-de-obra familiar - bem como a migração temporária para o assalariamento rural ou definitiva para as cidades - a produção com valor de uso (como o autoconsumo), as relações não monetárias (como trocas e doações de alimentos e trabalho).

Portanto, o capital não proletarizou e não separou a totalidade dos trabalhadores de seus meios produtivos. Mas os que não sucumbiram nesse processo não eram considerados pré ou anticapitalistas. 
Ao contrário, viviam em determinados espaços criados pelo capital para sua reprodução social. "A partir de um certo momento, a dinâmica do capital é que direciona as transformações e não mais a dinâmica da transição de um modo de produção para outro." (WANDERLEY, 2009, p.96).

Tendo como categoria básica a propriedade, Wanderley (2009, p.100) complementa que os territórios de camponeses que seriam supostamente livres das marcas da exploração dos senhores feudais, na passagem do feudalismo para o capitalismo, passam a sofrer as violências da propriedade privada e da acumulação do capital. Ou seja, a partir de então, o destino do campesinato e da agricultura em geral foi depender das leis do capital. Assim, mesmo proprietário da terra e dos meios de produção, o campesinato é subordinado ao capitalista que se apropria da renda de sua terra e do seu sobre trabalho.

Conclui a autora que devemos pressupor que o campesinato no Brasil é reproduzido pelo capital por causa do espaço estreito que ele oferece para as estratégias dos camponeses. Essa é a condição camponesa, condição de sua autonomia e liberdade. O capitalismo no Brasil se reproduziu pelos latifúndios, pela organização da produção em monoculturas, com trabalho escravo e para o mercado externo. O Estado teve (e tem) papel preponderante na reprodução desse modelo e, em seu interior, o campesinato é forçado a lutar para não desaparecer. Dificilmente temos camponeses "puros", ou seja, livres de qualquer influência do Estado e do mercado, que vivem alheios a sua existência e que não sofrem suas interferências geração após geração. Qual campesinato, enquanto grupo social, não teve nunca relações de trabalho em função da grande propriedade, ou sofreu da regulamentação estatal e da normatização por meio de leis, apesar de manterem uma força de trabalho familiar e a produção de sua própria subsistência?

Conforme Milton Santos (1998), a racionalidade capitalista invade e submete a todos indepen- dentemente de estarem ou não diretamente ligados a ela. Assim, a situação jurídica das terras, o pagamento de impostos, o uso de recursos naturais e vários outros direitos e regulamentações sociais, como o matrimônio, se associam à racionalidade capitalista e à vontade das classes burguesas que dominam o Estado. Como diz Moura (1986), é controlando o Estado que as classes dominantes dispõem dos instrumentos jurídicos e políticos que disciplinam inclusive o camponês, que impõem condições concretas às diversas categorias sociais, até as mais dispersas. Com isso, garante-se “(...) o fluxo contínuo e estável das rendas camponesas às classes rurais e urbanas com poder econômico" (MOURA, 1986, p.15).

Os camponeses se encontram em uma posição em que existe concretamente a apropriação de seu sobre trabalho, por meio do mercado capitalista. Embora seus efeitos sejam os mais diversos entre uma infinidade de situações singulares, cabe destacar que nessas situações há em comum uma margem para a livre deliberação conforme seus interesses e a manutenção de aspectos de uma economia não capitalista, que tem base em produções com valor de uso, em trabalho não monetário e em relações de produção comunitárias e solidárias. Para Wanderley, essa condição existe tanto para aqueles totalmente fora da grande propriedade quanto para aqueles assalariados rurais e se expressa nas lutas pela reforma agrária e nas estratégias familiares de pequenos produtores, que buscam maior autonomia em suas práticas sociais, porém, dentro dos limites de conjunturas específicas.

\section{ARMADILHAS DE INTERPRETAÇÃO}

É o campo [social] que designa a cada agente suas estratégias, ainda que se trate da que consiste em derrubar a ordem cientifica estabelecida. (BOURDIEU, 1983, p.138). 
próprias mercadorias e possui uma margem de autonomia em seu fazer cotidiano, há que se atentar para dois riscos dessa interpretação. Uma, a superestimação do autoconsumo e da autossuficiência em relação ao mercado. Se nem todos os itens necessários à sobrevivência podem advir de uma produção própria e exigem o dispêndio financeiro, supõe-se que a quantidade de trabalho e a produção devem ser superiores à subsistência. E a quantidade de renda, consequentemente, depende do preço obtido em uma relação nem sempre (ou quase nunca) favorável ao camponês. Logo, o excedente não representa aquilo que excede suas necessidades básicas, mas sim a complementação de seus meios de vida mediada pelo mercado. A relação com o mercado passa a ser um fator fundamental para sua reprodução social e seu trabalho excedente é direta e indiretamente mediado por essas relações. $\mathrm{O}$ caráter da alternatividade entre consumo e venda da produção não é fruto simplesmente de uma escolha individual, senão como necessidade para se garantir os itens necessários à reprodução. Para Wanderley, “(...) a organização do trabalho familiar depende, cada vez mais, dos mecanismos estruturais do mercado." (2009, p.123).

Tal efeito de mercado é sentido não apenas na comercialização de seus produtos. Com o avanço do capitalismo e da ideologia industrial nas regiões, pelo interior do Brasil, surgem cada vez mais constrangimentos impostos aos camponeses. Wanderley exemplifica o aumento do controle da produção de soja e de milho na Alta Mojiana paulista por grandes empresas nacionais e multinacionais, quando o efeito da centralização da produção transformou os camponeses em integrados. Com isso, eles passaram a ser os responsáveis pela produção agrícola, embora o controle das tecnologias (sementes, tratores, agrotóxicos e venenos) e dos seus preços, das práticas agrícolas empregadas, as formas de trabalho assalariado e a comercialização, o nível da matéria-prima exigida, os prazos da produção e o próprio preço da terra eram controlados por grandes investidores e corporações multinacionais. Conforme Moura (1986, p.64):

A renda territorial capitalizada vincula imediatamente a atividade produtiva camponesa aos requisitos da reprodução ampliada do capital e às leis do mercado. O camponês passa a se vincular ao movimento do capital, na condição de produtor de mercadorias ou mesmo de trabalhador para o capital industrial, mesmo que continue habitando sua parcela de terra.

O camponês permaneceu necessário para a reprodução do capital, afinal os capitalistas não tiveram, no caso mencionado sobre a Alta Mojiana, tanto interesse em possuir as terras e se verem obrigados a assumirem diretamente todos os investimentos da produção. Isso ficou a cargo dos camponeses, transferindo a eles os riscos desse investimento. $\mathrm{O}$ que o capitalista mais queria era obter a renda da terra e do sobre trabalho camponês. No caso das grandes corporações, atualmente mais interessa dominar os impérios alimentares (VAN DER PLOEG, 2008) - ou seja, corporações que detêm empresas que produzem desde as patentes das tecnologias do pacote agrícola, como sementes, adubos e fertilizantes ao beneficiamento, industrialização e comercialização de alimentos e remédios - do que possuir a terra em $\mathrm{si}^{4}$. Assim podem impor tecnologias e sistemas produtivos, distinguir os camponeses capazes à integração por capacidade produtiva e financeira que terão sua renda e trabalho explorados, excluindo os incapazes da terra

${ }^{4}$ No entanto, é bom lembrar que Sauer e Leite (2012) demonstraram os mecanismos de dominação das terras brasileiras pelo mercado imobiliário capitalista com a "estrangeirização" das terras em decorrência de investimentos de empresas do setor financeiro nos complexos da soja, da cana e da mineração. Sobretudo nas regiões da Amazônia e do cerrado, servindo tanto para estoque de terras para a expansão capitalista como para uma supervalorização imobiliária, esses investimentos entram em conflito aberto com os movimentos sociais das populações que ocupam esses territórios e com ambientalistas. Nesse sentido, o capital financeiro internacional é que controla a terra e a agricultura, nos casos da soja e da cana, por meio de todo o pacote agrícola da produção, o beneficiamento, a logística de escoamento, enfim, toda a cadeia produtiva. 
e concentrando essas parcelas.

Essa também é uma condição camponesa de permanência na terra, pois o capitalismo, ao invés de expropriar, integra uma parcela de produtores nas cadeias agroindustriais (MOURA, 1986). Em estudos recentes em assentamentos rurais verificam-se as relações assimétricas e desfavoráveis aos camponeses nas integrações agroindustriais. Isso implica na recriação da lógica familiar de reprodução social, em transitar por estratégias produtivas entre a autonomia e a dependência (FERRANTE; BARONE; DUVAL, 2008; GÊMERO; QUEDA, 2013; DUVAL; FERRANTE; BERGAMASCO, 2015a).

Apesar de estratégias e contextos regionais diferentes, o que aproxima os camponeses e trabalhadores rurais enquanto classe são as relações de propriedade e o controle dos frutos de seu trabalho, pois há o temor da completa proletarização e do cativeiro nas fábricas (VELHO, 2009). Mesmo se submetendo a situações de subordinação, lhes interessa a possibilidade de garantir a existência imediata, conforme mencionou Palmeira (2009), com um espaço no qual possa "botar seu roçado" e se reproduzir socialmente. A gradativa perda dessa possibilidade não o faz renunciar ao desejo de possuir esse local, no qual tenha, ainda que com poucas margens de autonomia, controle sobre seu tempo, trabalho e frutos. Enquanto não há um lote de terras que seja seu, por propriedade ou por direito, o temor ainda os ronda e, mesmo após essa conquista, seu futuro estará sempre vinculado à especulação capitalista. Por isso, é constante a luta pela terra que está no horizonte dessa possível classe social.

Outro texto interessante para resgatar essa problemática é o de Delgado (2004). Sem falar em campesinato ou classe social nesse texto, o autor prefere discutir os grupos rurais como parte do setor de subsistência da economia brasileira. $\mathrm{O}$ autor resgata a gênese do setor de subsistência na economia e na sociedade brasileira desde a história colonial até os dias atuais, ressaltando sua relevância para o país. Apoiando-se em três grandes historiadores econômicos brasileiros - Caio Prado Jr., Celso Furtado e Raimundo Faoro, que não utilizam a terminologia campesinato por verem a economia de subsistência como residual e dependente -, Delgado descreve o setor de subsistência como irrelevante na teoria social. Ele não era considerado parte fundamental da economia colonial, pois esta era apoiada no latifúndio, no trabalho escravo e na monocultura para exportação.

$\mathrm{Na}$ teoria social, o setor de subsistência era considerado um mero apêndice da grande economia, completamente dominado pelo setor da agro exportação. Pior que isso, era sinônimo de economia atrasada, um aspecto residual na constituição da sociedade brasileira moderna. Apesar dessas alcunhas, era reconhecidamente importante por ocupar parte da população e por prover o abastecimento interno da colônia, dentro e fora das fazendas e plantations. Nesse sentido, Delgado vai por uma linha interpretativa que procura explicitar a unidade contraditória dos latifúndios, que promoviam a produção direta de meios de vida, mas, sobretudo, a produção para o mercado e o desenvolvimento pela atividade agrícola mercantil. A sociedade brasileira com uma parcela da população de homens livres, porém expropriada dos meios de produção. Sem dissociar a contradição no interior dos latifúndios por haver neles uma complementaridade com o setor de subsistência, Delgado procura localizar a posição desse setor na estrutura social.

O conhecimento sobre o setor de subsistência é necessário para se conhecer o "Brasil profundo" e as relações das pessoas sem direito à terra com os senhores de terras, um dos pilares fundamentais da enorme desigualdade social no Brasil. Sem essa compreensão, fica capenga a interpretação da sociedade e da economia brasileira: “(...) os problemas contemporâneos de desigualdade, marginalização e pobreza parecem insondáveis, aparentemente efeitos sem causa." (DELGADO, 2004, p.18). 
$\mathrm{O}$ autor faz um esforço para não associar as pessoas no setor de subsistência ao que poderia caracterizá-las como resquícios de um campesinato europeu ou de sociedades indígenas da América, pois para ele ambas foram destruídas pelo capitalismo. Embora reconheça que tais pessoas possuam raízes nessas categorias, já que o texto fala de pessoas que retiravam seus meios de subsistência da economia secundária e dessas relações de trabalho há mais de 200 anos no Brasil. É essa categoria que ele afirma não desaparecer ao longo de todo o período do Brasil colônia aos dias de hoje:

(...) o setor de subsistência desempenhou o papel ocupacional principal na economia colonial; cumpriu função primordial na passagem do regime escravista para o de trabalho livre, na República Velha; e que, finalmente, no longo ciclo de industrialização do pós-guerra, o mercado de trabalho formal avançou, mas nem de longe logrou dissolver o setor de subsistência. Por fim, quando se exaure o ciclo de industrialização intensiva do pós-guerra, o setor de subsistência volta a crescer. (p.27)

\section{(...)}

No entanto, a experiência brasileira da modernização da agricultura no pós-guerra, e especialmente nas décadas de 1960 e 1970, embora gerasse uma maciça transferência de força de trabalho para o setor urbano, não eliminou o setor de subsistência no espaço rural, nem alimentou apenas um mercado de trabalho urbano-industrial. Constituiu-se enorme setor informal de trabalho urbano, que, embora não tenha as mesmas características do setor de subsistência, não é tampouco um setor assalariado. Tal fato já ocorria no auge do ciclo expansivo e magnificou-se bastante nas duas décadas de estagnação - 1980 e 1990 (p.28).

\section{(...)}

Na realidade, o que as teorias de desenvolvimento do campo conservador e do marxista não previram foi a reprodução urbana, em escala ampliada, de relações sociais similares às do setor de subsistência rural na chamada economia infor- mal-urbana, enquanto no espaço rural o setor de subsistência manter-se-ia intacto, depois do ciclo da modernização técnica do período de 1965-1985. (p.28).

Prado Jr., por exemplo, reconheceu as diferenças fundamentais e primárias de cada uma das categorias econômicas: por um lado, a grande economia agroexportadora dependia da agricultura de subsistência por razões óbvias de abastecimento interno. Mas os espaços que lhes eram atribuídos dependiam parcial ou exclusivamente da grande lavoura e das relações de propriedade. Na economia de subsistência, os agricultores gozavam de "certa autonomia", comparando-se com aqueles que trabalhavam na grande lavoura (DELGADO, 2004, p.8). Celso Furtado, por outro lado, chegou a reconhecer suas funções econômicas e não econômicas exemplificadas numa produção prioritariamente de valor de uso extremamente importante ao país em momentos de crises mercantis internacionais, apesar de sua baixa capacidade de gerar excedentes monetários ${ }^{5}$. Para Delgado (2004), o mais importante a destacar com base nesses autores são as relações de trabalho no setor de subsistência. Ambos reconheceram que, no interior das plantations, havia um expressivo contingente de pessoas que se abrigava (ou albergava, como diz o autor) nesse setor de subsistência e que tinham a possibilidade de trabalhar em outros cultivos (de alimentos) que não eram a atividade principal da fazenda (as commodities).

Linhares e Silva (2009) abordam essa problemática em um texto cuja análise volta-se à agricultura de subsistência e seus mecanismos em termos de formação de mercados internos, bem como aspectos ${ }^{5}$ Delgado (2004) menciona a relevância do setor de subsistência em quase um século de estagnação econômica no comércio exterior, entre a segunda metade do século XVIII e aproximadamente 1850. Por outro lado, em uma microescala, nas fazendas de borracha na Amazônia a produção de subsistência adquiriu relevância para a manutenção do sistema com o declínio no preço da borracha (ESTERCI, 2001). Ou seja, nesses momentos cíclicos de crise econômica a produção de subsistência adquire forte relevância para a economia e a sociedade do país. 
da legislação que lhe foi pertinente no Brasil colônia. Os autores concordam que a agricultura de subsistência era subordinada e secundária à produção da agricultura comercial de agro exportação, pois esta sim justificava os investimentos na colônia. Porém, considerando a importância da produção de alimentos para a colônia, os autores ressaltam a existência dessa produção tanto nas fazendas, para auto abastecimento de trabalhadores e patrões, como nas pequenas e médias propriedades para autoconsumo e venda dos excedentes aos núcleos urbanos em formação - o pequeno comércio e manufaturas, a burocracia estatal e militar, entre outros que abrangiam um mercado consumidor para esses produtos. Os autores consideram, portanto, sua importância na constituição dos mercados internos nas regiões, mas que só ganha atenção em momentos críticos para a economia colonial.

Se para esses autores era impossível conceber a constituição de camponeses livres em relação às monoculturas e às formas dominantes de distribuição de terras, não foi possível restringir o enraizamento de "homens livres pobres ou negros fugidos" em determinadas posições sociais. Linhares e Silva (2009) usam o termo "protocamponeses", para designar as "brechas camponesas" no sistema escravista. A possibilidade de trabalho para a própria subsistência e uma produção de excedentes marca essa possibilidade no interior, no entorno e longe das fazendas. É a existência da pequena produção e suas formas de organização que assemelha os escravos e pobres rurais aos camponeses. Mas a relação desses supostos camponeses com o Estado e com os latifundiários, bem como com os demais agentes sociais, sobretudo os do mercado, também marcam tais semelhanças. A possibilidade dessa produção teve sempre estrita dependência com tais agentes.

Nesse sentido, para Linhares e Silva (2009) existiam três quadros distintos de situações camponesas no Brasil: as relações escravistas "clássicas" e em seu interior as brechas camponesas. No entorno das fazendas, outros camponeses (marginais) se es- tabeleceram lavradores que produziam cana para os engenhos e outros gêneros que abasteciam os mercados locais. Posseiros que se integravam ao algodão no nordeste são outro exemplo dessa condição camponesa. Outros pequenos produtores mais isolados nos sertões, sobretudo com a produção pecuária, caracterizavam-se camponeses de fronteira.

Já na transição do trabalho escravo para o assalariado, Delgado (2004) revela com base nos Censos Econômicos que o grande contingente do setor de subsistência permaneceu praticamente intacto, mantendo algumas de suas características, mas também recriando novos perfis. O setor de subsistência expressava atividades econômicas e relações de trabalho que fugiam às categorizações de trabalho escravo ou assalariado. Suas características mais evidentes eram a produção de alimentos e, sobretudo, a dependência direta e indireta em relação aos grandes proprietários de terras, conforme mostra a passagem a seguir:

\begin{abstract}
Esse setor de subsistência sobreviveu à abolição da escravatura, entre outros fatores, por ser um subsistema independente do escravismo e, de certa forma, ser também autônomo relativamente à monocultura exportadora - embora não o seja em relação ao regime fundiário vigente. (DELGADO, 2004, p14).
\end{abstract}

A partir de 1930, houve uma necessidade de re-conceituar o setor de subsistência, segundo Delgado (2004, p.22), como:

(...) o conjunto de atividades econômicas e relações de trabalho que propiciam meios de subsistência e/ou ocupação a uma parte expressiva da população, mas tais relações não são reguladas pelo contrato monetário de trabalho assalariado, nem visam primordialmente à produção de mercadorias ou de serviços mercantis com fins lucrativos.

Apesar de ter permanecido ignorado na história oficial do país, o setor não desaparece. Primei- 
ro, porque não houve uma completa transição de trabalhadores agrícolas para o assalariamento, mas se mantiveram milhares de trabalhadores sem vínculos formais de trabalho no campo e na cidade. Segundo, por permanecerem aquilo que essa linha interpretativa reconhece como os agricultores de subsistência - ou uma camada de camponeses que facilmente poderíamos indicar com base em suas principais características, a partir daquilo que chamamos de condição camponesa. Os problemas não resolvidos até então são tratados por meio da modernização conservadora pelo regime militar, ou seja, modernização da base técnica sem alterar as relações de propriedade. Para aqueles do setor de subsistência, tratou-se da tentativa de alinhá-los às estratégias do agronegócio que, para Delgado (2004), em nada favoreceu sua absorção.

Mais recentemente, surgiu a noção de agricultura familiar ligada à aplicação de políticas públicas para famílias de trabalhadores rurais. Apesar de tocar a realidade vivenciada pelos camponeses e pelos grupos sociais atrelados ao setor de subsistência da economia brasileira, as ações públicas se dão mais em relação àquelas famílias alinhadas ao ideário da modernização da produção. Essa problemática pode igualmente repor armadilhas interpretativas, objeto de outros textos acadêmicos (DUVAL; FERRANTE; BERGAMASCO, 2015b).

\section{CONSIDERAÇÕES FinAis}

As armadilhas interpretativas que o texto discute se referem à negação do campesinato brasileiro e a de que os camponeses iriam simplesmente desaparecer. Esta última estava na tese de que a integração do meio rural no sistema capitalista se daria com a modernização conservadora do campo e, com o tempo, o rural perderia as formas explicativas de diferenciação: tudo seria parte de uma sociedade urbanizada e industrializada, inclusive o que há no meio rural. Tal premissa teórica vai ao encontro do estudo de Bourdieu (2004), que mostrou que o avanço da racionalidade burguesa-industrial atingiu os mercados materiais e simbólicos dos grupos sociais rurais, enfraquecendo-os objetiva e subjetivamente. A tendência geral, bem como o que ocorria individualmente, era o fim dos grupos rurais. No entanto, os autores foram obrigados a reconhecer, com relação ao processo de dissolução do campesinato, a maior lentidão do processo de industrialização (concentração e centralização) na agricultura, sobretudo tendo-se em vista as manobras e resistências do campesinato frente às pressões dos capitalistas, dos latifundiários e do Estado.

No confronto entre as duas formas de produção - capitalista e camponesa -, são reconhecidas as diferenças da capacidade de socialização da produção na forma de exploração camponesa e seu caráter familiar. Porém, o desenvolvimento das forças produtivas capitalistas no campo provoca uma conversão do campesinato ou em burguês, relativamente proprietário dos meios de produção ou proletário rural que vende sua força de trabalho. Assim, os camponeses originais se tornariam resquícios anacrônicos. Ao atribuir ao futuro da agricultura um caminho inexorável rumo à industrialização - a agricultura apenas como um ramo da indústria e os camponeses como operários -, parece haver indícios de que o modo de produção camponês é aquele pré-capitalista, uma antessala da industrialização da agricultura na transição do feudalismo ao capitalismo ou apenas uma forma primitiva de produção na agricultura.

No entanto, podemos afirmar que uma série de características do modo de vida camponês, da produção e da reprodução social de grupos rurais como indígenas, quilombolas, ribeirinhos, faxinalenses, dentre tantas diferenças, permanecem vivas e passam por um processo de reconhecimento de seus direitos por grande parte da sociedade civil. Muitos grupos sociais, inclusive, reivindicam o modo de vida camponês como componente político-ideológico, ao se afirmarem camponeses e, atualmente, este debate 
estimula uma importante reflexão sobre os temas da reforma agrária, da segurança e da soberania alimentar e hídrica, da agricultura sustentável, dos mercados justos e da alimentação saudável.

Apesar de alguns autores negarem a existência do campesinato no Brasil - seja pela opção por uma agricultura mais tecnificada e/ou concentrada, seja pelo não reconhecimento político, jurídico, econômico, social e cultural de pessoas que vivem no campo e se intitulam camponesas ou porque creem que alguns grupos rurais mais empobrecidos não têm chances competitivas nos dias de hoje ou, ainda, porque essas pessoas não poderiam ser chamadas de camponesas em sua acepção conceitual, pois seria inoportuno haver camponeses no Brasil ou mesmo porque isso representaria uma volta ao passado -, no presente artigo procuramos distinguir elementos da gênese do campesinato brasileiro, que embasam uma "condição camponesa" de natureza contraditória, mas que se faz presente no interior das sociedades dominadas pela racionalidade capitalista e, inclusive, persiste nas áreas rurais e nos grupos sociais. Características da condição camponesa resistem em grande variedade e diversidade de grupos sociais, identificados no campo e na cidade enquanto classe subalterna e/ou setor de subsistência.

Cabe ressaltar que tais armadilhas de interpretação não podem gerar leituras insuladas no plano teórico somente, como produto de uma bibliografia por muitos considerada superada, o que contestamos ao longo do texto. Aceitar a condição camponesa na racionalidade capitalista se faz necessário, se a opção for pelo reconhecimento de que o desenvolvimento rural não se expressa por linearidades, mas pelas singularidades, descontinuidades e recomposições dos seus agentes sociais. É importante não perder de vista estas armadilhas de interpretação e as invisibilidades que parecem anular a importância que a condição camponesa tem nos rumos do desenvolvimento rural. Tal posição exige considerar os preconceitos e o quase desconhecimento que permeiam a ação do Estado nas suas parcas iniciativas de apoios institucionais para estes grupos rurais. Que o Brasil de hoje e o de amanhã não transformem os frutíferos programas institucionais de compra de alimentos e de assistência técnica aos camponeses em outra armadilha de subalternidade.

\section{REFERÊNCIAS BIBLIOGRÁFICAS}

BOURDIEU, P. O Campo Científico. In: ORTIZ, R. (Org.) Bourdieu - Sociologia. Coleção Grandes Cientistas Sociais, vol. 39. São Paulo: Ática, 1983, p.122155

. El Baile de los Solteros. La crisis de la sociedad campesina en el Bearne. Barcelona: Anagrama, 2004.

CÂNDIDO, A. Os Parceiros do Rio Bonito. Estudo sobre o caipira paulista e a transformação dos seus meio de vida. $5^{\text {a }}$ ed. São Paulo: Duas Cidades, 1979.

DUVAL, H.C. Bens Materiais e Simbólicos: condição camponesa e estratégias familiares em assentamentos da região central do estado de São Paulo. Tese (Doutorado em Ciências Sociais). Instituto de Filosofia e Ciências Humanas, Universidade Estadual de Campinas, Campinas, 2015.

; FERRANTE, V.L.S.B.; BERGAMASCO, S.M.P.P. Estratégias familiares entre a dependência e a autonomia no campo social dos assentamentos rurais da região central do estado de São Paulo. III Seminário Internacional Ruralidades, Trabalho e Meio Ambiente, 2015, São Carlos. In: Anais, São Carlos, 2015a.

Sobre o uso da teoria do campesinato na contemporaneidade. Raizes (UFPB), Campina Grande, v.35, p.62-78, 2015 b.

DELGADO, G.C. Setor de Subsistência na Economia Brasileira: gênese histórica e formas de reprodução. Questão Social e Políticas Sociais no Brasil Contemporâneo. Textos para discussão, IPEA, Brasília/DF, 2004, p.19-50.

ESTERCI, N. A ilusão do trabalho livre. In: ESTERCI, N.; FRY, P.; GOLDENBERG, M. (Orgs.) Fazendo Antropologia no Brasil. Rio de Janeiro: DP\&A, 
2001, p.265-294.

FERRANTE, V.L.S.B. A Proletarização não tem cartas marcadas: a terra no horizonte dos boias-frias. $R e$ vista Reforma Agrária, Campinas, v.22, n.3, p.16-23, 1992.

.; BARONE, L.A.; DUVAL, H.C. O preço amargo das parcerias dos assentamentos com as agroindústrias. Retratos de Assentamentos, Araraquara, v.11, p. 21-44, 2008.

GARCIA JR., A.R. Terra de Trabalho. Trabalho familiar de pequenos produtores. Rio de Janeiro: Paz e Terra, 1983.

GÊMERO, C.G.; QUEDA, O. Assimetria nas relações de trabalho e renda entre os assentados da região de Araraquara e as agroindústrias do setor avícola. Retratos de Assentamentos, Araraquara, v.16, p.275309, 2013.

LINHARES, M.Y.; SILVA, F.C.T. A questão da agricultura de subsistência. In: WELCH, C.A.; MALAGODI, E.; CAVALCANTI, J.S.B.; WANDERLEY, $\mathrm{M}$ de N.B. (Orgs.) Camponeses Brasileiros. Leituras e interpretações clássicas, v.1. Brasília/São Paulo: NEAD/MDA e Unesp, 2009. p.117-134.

MARTINS, J. S. A sociedade vista do abismo. Novos estudos sobre exclusão, pobreza e classes sociais. 2. ed. Petrópolis: Vozes, 2002. Capítulo 2: Situações diferenciais de classe social. Operários e camponeses, p.49-117.

MENESES, M.A. Redes e Enredos nas Trilhas dos Migrantes: um estudo de famílias de camponeses migrantes. Rio de Janeiro: Relume e João Pessoa: Dumará/UFPB, 2002.

MOURA, M. M. Camponeses. 2. ed. São Paulo: Ática, 1986.

PALMEIRA, M. G. S. Casa e Trabalho: Nota sobre as relações sociais na plantation tradicional. In: WELCH, C.A.; MALAGODI, E.; CAVALCANTI, J.S.B.; WANDERLEY, M de N.B. (Orgs.) Camponeses Brasileiros. Leituras e interpretações clássicas, v.1. Brasília/São Paulo: NEAD/MDA e Editora Unesp, 2009, p.203-215.

QUEIROZ, M.I.P. de. O Campesinato Brasileiro. Ensaios sobre civilização e grupos rústicos no Brasil. $2^{\mathrm{a}}$.ed. Petrópolis: Vozes, 1976.
SANTOS, M. Técnica, Espaço, Tempo. Globalização e meio técnico-científico informacional. $4^{\mathrm{a}}$. ed. São Paulo: Hucitec, 1998. Cap. 2: A aceleração contemporânea: tempo-mundo e espaço-mundo, p.29-39.

SAUER, S.; LEITE, S.P. Expansão agrícola, preços e apropriação de terra por estrangeiros no Brasil. Revista de Economia e Sociologia Rural (Impresso), Brasília, v.50, p.503-524, 2012.

SIGAUD, L. Os clandestinos e os direitos: estudo sobre trabalhadores da cana-de-açúcar de Pernambuco. São Paulo: Duas Cidades, 1979.

THOMPSON, E. A Formação da Classe Operária Inglesa. Vol. II - A maldição de Adão. $2^{\text {a }}$ ed. Rio de Janeiro: Paz e Terra, 1987.

VAN DER PLOEG, J.D. Camponeses e Impérios Alimentares: lutas por autonomia e sustentabilidade na era da globalização. Porto Alegre: Ed. da UFRGS, 2008 .

VELHO, O.G.A.C. O conceito de camponês e sua aplicação à análise do meio rural brasileiro. In: WELCH, C.A.; MALAGODI, E.; CAVALCANTI, J.S.B.; WANDERLEY, M de N.B. (Orgs.) Camponeses Brasileiros. Leituras e interpretações clássicas, v.1. Brasília/São Paulo: NEAD/MDA/Unesp, 2009, p.89-96.

WANDERLEY, M. de N.B. Agricultura familiar e campesinato: rupturas e continuidade. Estudos Sociedade e Agricultura, Rio de Janeiro, v.21, p.42-61, 2003.

WANDERLEY, M. de N.B. O Mundo Rural Como Um Espaço de Vida. Reflexões sobre a propriedade da terra, agricultura familiar e ruralidade. Porto Alegre: Ed. da UFRGS, 2009. Apresentação, p.09-22. Capital e propriedade fundiária na agricultura brasileira, p.25-43. O camponês, um trabalhador para o capital, p.71-136. 